ISSN 2504-1916

VOL. 18/1 (2019), 1-15

doi: 10.5450/EJM.18.1.2019.01

\title{
Introduction: Music, Climate Change, and the North
}

\section{Britta Sweers, editor}

G laciers are the "climate thermometers" of the planet, providing insights into past climate changes and the current climate situation globally. What do these "thermometers" tell us about the climate in the second decade of the new millennium, given that ice, snow, and glaciers - the natural surroundings and conditions in the Northern hemisphere-are both conceptually and physically linked to climate change ${ }^{1}$ And what can one learn from listening to a Nordic perspective, as will be the focus of the articles in this EJM volume? ${ }^{2}$ The dramatic increase of natural disasters has raised global awareness of the interrelation between economic systems and natural resources, as is evident in current debates on climate change and global warming. ${ }^{3}$ Yet in light of the economically-driven political framework globally, arguments surrounding climate change and global warming have been challenged and questioned in many, especially Western countries to the extent of pure political denial, even though the melting of glaciers in the North and Alpine regions is clearly obvious. While some politicians may deny the world's climate change reality, there has been growing human awareness and reconnection to the natural environment over the last three or four decades, evident, for instance, in 2018 and 2019 in the School Strikes for Climate (also called "Fridays for Future" and "Youth Strike 4 Climate"), as well as in the shifting concept of "nature" over the past decade away from being a merely abstract opposite concept to culture and toward an essential asset of human existence. The following articles reflect this

\footnotetext{
${ }^{1}$ See, for instance, the websites of various university-based climate research institutions, e.g. of The University of Boulder ("All About Glaciers," https://nsidc.org/cryosphere/glaciers/questions/climate.html, accessed 7 November, 2018) or the output data of the Oeschger Center for Climate Research (OCCR) of the University of Bern (http://www.oeschger.unibe.ch/forschung/publikationen/index_ger.html; accessed 7 November, 2018), as well as the NASA website that clearly acknowledges the evidenced global warming process (https://climate.nasa.gov/evidence/, accessed 7 November, 2018).

${ }^{2}$ Some articles that were included here emerged from the Music \& Nature conference that was held in Kópavogur (Reykjavik, Iceland) from 22-24 May, 2011. See also the Introduction to the European Journal of Musciology vol. 15/1 (2016) for a broader background.

${ }^{3}$ This was already discussed before the turn of the millennium. See, for instance, Paul Hawken, Amory Lovins, and Hunter Lovins, Natural Capitalism: Creating the Next Industrial Revolution (Boston, New York, London: Little, Brown and Company, 1999).
} 
heightened awareness of environmental issues, while approaching climate change through the lens of music with particular focus on music and climate change in the North.

\section{The North: A Multi-Layered Concept}

At surface level, the North denotes a clearly identifiable geographical and environmental region, which is the focus of all articles presented here, either directly by discussing the music of Iceland and mainland Scandinavia, or indirectly by addressing the glacial mountain regions of the Himalayas, European Alps, and related environment of the Antarctic. Thus, the "North" denotes, as defined by the Random House Webster's College Dictionary, "the cardinal point of the compass," or, in other words, probably the most significant human point of spatial-geographic orientation. Taken from the old High German expression Nord, which was already in use before 900 A.D. and related to the Indo-Germanic ner= "down/under," the term connoted "left of the rising sun," indicating the position of a person looking towards the north. Yet "North" also carried synonym meanings, for example to refer to "midnight," since it indicated the sun's position at night, and was tied to the stellar constellations that served as major points of global and cosmic orientation for human beings. Indeed, the Roman expression septentrio, another synonym of "north," refers to the seven stars of the Great Bear; the seven-star asterism "Big Dipper" or "Grosser Wagen" (Ursa Maior in Latin) was constructed in relation to Polaris (North Star); and part of the constellation known as "Little Bear" is only forty four arc minutes over the North Pole. The word "bear" (arctos/adj.: arcticos) is clearly significant for the naming of the entire circumpolar region of North America, Asia, and Europe. Moreover, the Greek term Boréas, which represents the mythological personification of the (winter) north wind, is another recurring expression, be it with regard to the northern conifer woods (boreal forest) or the polar light (aurora borealis).

Thus while the geographical region of the North seems to be easily defined, at least at surface level, as a humanly constructed space the North is more difficult to grasp. Moreover, the earth's magnetic field — and, thus, the compass needle's reference point—and stellar constellations (even if at a slow pace) are shifting permanently, so consequently the concept of the North has shifted in its meanings constantly. The resultant large range of imageries and concepts related to the North is particularly apparent in music, most prominently in the ideas surrounding "Nordic music," as developed in the art music of Scandinavian composers Carl Nielsen (1865-1931), Edvard Grieg (1843-1907), and Jean Sibelius (1865-1957). ${ }^{5}$ Employing particular musical elements, such as modal scales that typically avoid tonal centers, a drone fundament, and folk music material, "Nordic music" has often been associated with the wide northern

${ }^{4}$ Robert B. Costello (Editor in Chief), Random House Webster's College Dictionary (New York: Random House, 1991), 923-924.

${ }^{5}$ For a broader historical overview see Frederick Key Smith, Nordic Art Music: From the Middle Ages to the Third Millennium (Westport, CT: Praeger, 2002). 
landscapes and its multi-faceted light effects, as well as a certain melancholic mood, which has indeed been a central marker of the "Nordic tone," also characterized by a highly reverberating, yet muted sound.

This Nordic tone or sound was shaped since the late twentieth century by Norwegian soprano saxophonist Jan Garbarek (b. 1947) and the landscape imagery that dominated his private record label ECM. The Nordic sound has since become a recognizable icon within art, jazz, and world music circles, even while it is a contradictory concept, as discussed in Katrin Losleben's article, and recurs as a concept in several of the other articles, in which the North is perceived predominantly as an environmental space that has sparked a specific sensitivity to climate change, which is expressed in musical and performative works.

\section{Climate Change from a Cultural and Musical Perspective}

Climate change - the other central music-related theme of this article collection-is clearly a physicalenvironmental phenomenon, yet it is also a cultural problem and deeply embedded in human experience, which is clearly reflected in human artistic expression, such as music making. As is argued here, the study of music making provides profound access to the often unconsciously used and/or hidden idea(s) of "nature," particularly within the epoch of "the Anthropocene," as described by ecologist Eugene F. Stoermer and atmospheric chemist Paul Crutzen in $2000 .^{6}$ In nearly all cultures, nature and music are closely intertwined. Not only does nature provide the materials for musical instruments, natural resources also provide the foundation for musical/sound-based ideas and subjects for compositions and performances. Many cultures, artists, and composers have thus reflected on the relationship between humankind and nature in their performances and works, while revealing the consequences of "humans as part of nature," working out ideas surrounding nature, and exploring new ideas, such as "nature as part of humankind." Either way, they remind us that the relationship between humankind and nature has to be redefined in times of climate change and global warming.

Analyzing the role of music and artists' voices in the process of contemporary ecological transformation, this EJM volume not only contributes musicological perspectives to international discourses on climate change, but also closes the gap between the sciences and humanities still evident at international climate conferences. The experience of the loss of human unity with nature in the nineteenth century has been increasingly compensated in the West with the apotheosis of nature in music

\footnotetext{
${ }^{6}$ See Paul Crutzen and Eugene F. Stoermer, "The Anthropocene," IGPB [International Geosphere Biosphere Programme] Newsletter 41 (2000): 17. However, the expression that is often used informally in a scientific context, was already in use before that publication. Its beginning is difficult to date, ranging from human impact around 15,000-14,000 $\mathrm{BC}$ or the Industrial Revolution around 1780 to the Trinity test (the first test of a nuclear bomb in 1945. See also the interdisciplinary journal The Anthropocene Review (SAGE) for a deeper insight into the related debates.
} 
and art, while many local and indigenous cultures have been reviving and appropriating this topic increasingly in recent years.

The articles in this volume, and specifically Aaron S. Allen's reflection on ecomusicology, all demonstrate that musicology and music, in particular, have something to contribute to the climate debate, which is all too often still dominated by the natural sciences. Indeed, as Canadian anthropologist Julie Cruikshank indicated in her seminal discussion of indigenous knowledge in the glacial world of Alaska, Do Glaciers Listen?, it will be an important challenge to communicate this knowledge among the vast canon of voices on global climate change, given that "environmental politics have so normalized our understanding of what 'nature' means, that we can no longer imagine how other stories might be significant." ${ }^{77}$ While ethnomusicological knowledge often refers to local knowledge, e.g. of a community, of a region, or of a specific genre, the natural sciences would easily gloss over local knowledge by pointing their emphasis on the larger global climate and on physical and political issues. Yet, the stories told in the following articles about traditional songs, performance practices, and compositions all provide deep reflections and local knowledge on nature. For instance, Tina K. Ramnarine's article clearly reflects that human environmental consciousness manifests itself significantly, if not even most and foremost, in aesthetic forms of creative expression.

When faced with the not unlikely possibility that humanity, rather than the planet, might be gone, could one even go as far as to argue that cultural knowledge-irregular, non-comparable, and vague, as it seems - might be the true significant "data"? Conveying a large range of human ways of interacting with nature, cultural knowledge appears hugely important for long-term human survival on this planet. Moreover, the course taken by the climate debate during the second decade of the new millennium, increasingly points towards failure. A growing number of publications with titles such as Grounding Global Climate Change by Heike M. Greschke and Julia Tischler or How Culture Shapes the Climate Debate by Andrew J. Hoffman, and column headlines like "Why we are poles apart on climate change," ${ }^{8}$ shows that the climate debate has long turned away from the discussion of hard scientific facts, and has rather becomeparticularly on a public level_an ideological debate centered on defending subjective values. For example, Hoffman points out in his critical analysis of the ongoing climate debate ${ }^{9}$ that the conversations

\footnotetext{
7 Julie Cruikshank, Do Glaciers Listen? Local Knowledge, Colonial Encounters, and Social Imagination (Vancouver: UBC Press, 2005), 258.

${ }^{8}$ Heike M. Greschke and Julia Tischler, ed., Grounding Global Climate Change: Contributions from the Social and Cultural Sciences (Dodrecht, Heidelberg, New York, London: Springer, 2015); Andrew J. Hoffman, How Culture Shapes the Climate Debate (Stanford, CA: Stanford University Press, 2015); Dan Kahan, "Why we are poles apart on climate change: The problem isn't the public's reasoning capacity; it's the polluted science-communication environment that drives poles apart," Nature (15 August, 2012). http://www.nature.com/news/why-we-are-poles-apart-onclimate-change-1.11166 (accessed 1 August, 2018).

${ }^{9}$ Andrew J. Hoffman, How Culture Shapes the Climate Debate (Stanford: Stanford University Press, 2015).
} 
have become battles between opposing sites, more focused on employing the best rhetoric than on the development of sustainable strategies. Analyzing the motivations of what actually makes people accept and reject arguments in his study on How Culture Shapes the Climate Debate, Hoffman depicts the cultural lenses through which science is interpreted. The following articles show that music is a similarly important tool for deeper analyses of this debate, even more so in an era increasingly dominated by manipulated data or "fake news" or related accusations in the face of criticism, while posing new challenges to the handling of and belief in "hard facts." The situation thus calls for intensified collaborations between the cultural sciences and their natural scientific counterparts. Indeed, applied ethnomusicology illustrates ${ }^{10}$ that the act of listening, mediating, and interacting is a skill inherent in the cultural sciences, so scientific exchanges may be more than fruitful, not only through research, projects, empowerment of groups, and mediation between different institutions, but by taking on more active roles in the debate on climate change, especially at a time in which science and education have become dominated by neoliberal thinking and politics. ${ }^{11}$ It is through the kind of research as presented in this EJM volume that true solutions to real environmental problems may be found.

\section{Climate Change in the North from a Musical Perspective}

This EJM volume brings together three broader musical perspectives on climate change in the North: the experience of place, climate change from a female viewpoint, and sustainability, and each perspective will be introduced in this final section. The musical perspective makes particularly apparent that a concern with the changing environment is intertwined with the often simultaneous yet contradictory experience of people's fear of nature and fascination with nature. As Denise Von Glahn pointed out in The Sounds of Place with regard to North America:

At the beginning of the new century, we live in a convulsed wilderness of our own making, one that harbors unimaginable dangers. But it is one that also houses the same natural wonders that first captured the imagination of explorers more than three hundred years ago. ${ }^{12}$

Von Glahn's observation not only applies to the American landscape historically, but, considering different timeframes, also to today's global culture. At the same time, the sounds of a place continuously

\footnotetext{
${ }^{10}$ Svanibor Pettan and Jeff Todd Titon, ed., Oxford Handbook of Applied Ethnomusicology (New York, Oxford: Oxford University Press, 2015).

11 See also Henry A. Giroux, Neoliberalism's War on Higher Education (Chicago, Illinois: Haymarket Books, 2014).

${ }^{12}$ Denise Von Glahn, The Sounds of Place: Music and the American Cultural Landscape (Boston: Northeastern University Press, 2003), 272.
} 
change as much as the places of sound-in the physical world, but also in mentally imagined realities. As Tina K. Ramnarine's article here indicates, the issues discussed in this volume are neither restricted to specific performance practices, nor to specific cultures or musical styles and genres, but they involve anyone and anything, musically speaking. Consequently, the articles not only transgress genre-related divides by including classical and modern composers, as well as pop, rock, folk, and folk rock musics and musicians. The volume also presents a heterogeneous mix of academic perspectives from Europe and North America, along with different perspectives ranging from cultural philosophy to music analysis, and approaches informed by cultural theory and music aesthetics.

\section{Place, Music, and Climate Change in the North: Three Reflections}

Arctic locations like Iceland are a reminder of the highly heterogeneous and varied environment of the North, yet at a closer look they share several common transregional features. This not only includes the seasonal extremes of light that reflect the harsh environment and only allow a limited, if at all, time for agricultural cultivation, but also represents an environment that, in Europe at least, has been shaped by oceanic impacts and the persistent presence of snow and ice. The Arctic is highly fragile and extremely prone to the impact of global climate changes, which, as various authors emphasize, significantly effect the local experience of a sense of place. While the analysis of terms such as place and space has been increasingly established in anthropology ${ }^{13}$ and ethnomusicology ${ }^{14}$ since the mid-1990s, the impact of climate change on the alteration of place and the experience of place has only become a central topic in the second decade of the new millennium in various disciplines. Given that humans are place-attached and develop place-bound identities, the influence of the ongoing climate transformation is apparent on multiple levels. For example, Cunsolo et al. (2012) discuss with regard to Inuit communities in Nunatsiavut (Canada) the way that climate-affected disruptions not only affect seasonal lifestyles, but also people's physical, mental, and emotional health and well-being. ${ }^{15}$ Further impacts are experienced at the economic and sociocultural level, and music and the arts are indeed central here.

This EJM volume illustrates that music and performance can provide deep insights into the environment. For example, given its outstanding natural context, Iceland's rich contemporary music

\footnotetext{
${ }^{13}$ For a broader overview see Adrian Pearce, "A Sense of Place, a Place of Senses: Land and a Landscape in the West of Ireland," Journal of Anthropological Research 61, no. 4 (winter 2005): 495-512.

https://doi.org/10.3998/jar.0521004.0061.403.

${ }^{14}$ Especially Martin Stokes, ed., Ethnicity, Identity, and Music: The Musical Construction of Place (Oxford, New York: Berg Publishers, 1994) has become a central reference point here.

${ }^{15}$ Ashlee Willox Cunsolo, Sherilee Harper, James D. Ford, Karen Landman, Karen Houle, and Victoria L. Edge, "'From this place and of this place:' climate change, sense of place, and health in Nunatsiavut, Canada," Social Science \& Medicine 75, no. 3 (August 2012): 538-47. doi: 10.1016/j.socscimed.2012.03.043 (accessed 9 November, 2018).
} 
culture $^{16}$ has frequently incorporated visual images of nature and the environment, which is most prominently evident in the work of Björk and Sigur Rós. Indeed, as pointed out by cultural scientist Tony Mitchell, Iceland represents a unique sonic geography or geomorphic soundscape that conveys specific environment-related sentiments, such as the "feeling of hermetic isolation." 17 Yet this poses the question of what can be and is actually represented in and through music? Referring to Sigur Rós's film Heimat (2007), a focus also shared in Phorbjörg Daphne Hall's article in this volume, Mitchell's psychogeographic analysis $^{18}$ addresses less a concrete or real soundscape, which is indeed incorporated in Sigur Rós's performances, but rather points to a more abstract atmospheric sonic experience created through a blend of melancholic images, specific modes, timbres, and rural and folklore elements, among others. ${ }^{19}$ These elements might be part of both a broader, "world music"-related context and indeed resemble real nature, not least due to the interrelation of sound and visual images. Yet they are neither identical to the actual local environment nor do they represent current music performances and preferences. As Fabian Holt therefore warns, ${ }^{20}$ the North is part of a globalized world, as expressed in the rich and multifaceted world of popular music, which in part deliberately moves away from an imagined North created through these means.

Deconstructing this imagined North helps to understand the locally and globally constructed sense of place and the impact of its transformation, which is not only relevant for the so-called Nordic tone created by Scandinavian composers and musicians and associated mostly with the regions south of the polar circle, but also for the actual Arctic and, since the nineteenth/early twentieth century, the Antarctic. Given that the circumpolar Arctic was historically an unknown, dangerous territory for most inhabitants, an understanding of how it became idealized as an unpolluted, untouched, and innocent Arcadia and associated with a specific atmospheric perception provides deeper insights into the ways in which environmental threats are addressed in music.

\footnotetext{
${ }^{16}$ Having long been a rather neglected field of study, Iceland's contemporary music cultures have been addressed by several publications in the second decade of the new millennium; e.g. Phorbjörg Daphne Hall, Nicola Dibben, Tony Mitchell, and Árni Heimir Ingólfsson, eds., Sounds Icelandic (Sheffield: Equinox, 2019); Fabian Holt and AnttiVille Kärja, eds., The Oxford Handbook of Popular Music in the Nordic Countries (New York, Oxford: Oxford University Press, 2017).

17 Tony Mitchell, "Sigur Rós's Heima: An Icelandic Psychogeography." Transforming Cultures 4, no. 1 (2009): $172-$ 198, here 172. https://epress.lib.uts.edu.au/journals/index.php/TfC/article/view/1072 (accessed 9 November, 2018). See also Mitchell's article for a good overview of literature on the concept of psychogeography.

${ }^{18}$ See Michell, "Sigur Rós" for a good overview of literature on the concept of psychogeography.

${ }^{19}$ Mitchell, "Sigur Rós."

${ }^{20}$ Fabian Holt, "Introduction: Music in a Globalizing Region," in The Oxford Handbook of Popular Music in the Nordic Countries, eds. Fabian Holt and Antti-Ville Kärja (New York, Oxford: Oxford University Press, 2017), 1-30.
} 
The articles by Aaren S. Allen, Katrin Losleben, and Phorbjörk Daphne Hall start with a theoretical reflection on the relationship between place, music, and climate change in the North. Each author illustrates how music and musical processes are the means by which place and environmental consciousness are experienced and articulated by individuals and society in more general. Going far beyond established concepts of the North and music genre boundaries, the authors approach the North conceptually by adapting concepts from philosophy and cultural studies. For example, Aaron S. Allen's article illustrates the history, approaches, and perspectives of economusicology, a term coined in 2008 by the author himself, along with multi-layered approaches toward understanding environmental issues and global climate change within ethnomusicology in general. Following this, Katrin Losleben's article on "Arctic Arcadia" provides a reflection on the parallels between modern environmental concepts of the North and of the antique pastoral Arcadia. Asking questions about the way the North represents the antique pastoral Arcadia, Losleben helps to understand how the concept of place has been shaped historically and culturally. Her analyses of antique philosophical and lyrical writings suggest that many significant keywords employed in the climate debates (and evident in modern compositional works) show clear parallels to these classical concepts. Losleben's article also provides insights into Arctic and Antarctic impressions through the work of sound artists Lawrence English and Werner Dafeldecker (Esperanza, 2010), Katie Paterson (Vatnajökull (the sound of)) and Langö̈kull, Snafellsjökull, Solbeimajökull, 2007), and Jamie Drouin (Perimeter:Sarichef, 2011-2013).

This focus is further expanded by Phorbjörg Daphne Hall's article on the modern relationship between humans and nature, while analyzing the case of "The Representations of Iceland and Icelanders" in the film Heima by Sigur Rós. Hall's article illustrates that, while nature is omnipresent in Iceland, the fragile relationship between humans and Arctic nature becomes even more visible here, highlighting how environmental concerns expressed through contemporary music are intertwined with aspects like ecocriticism, political activism, and sustainability (the latter issue will again be taken up in the last articles). Hall demonstrates that a musical (and visual artistic) reading of the surrounding environment can reveal hidden, often deviating attitudes towards nature conversation in broader society.

\section{Experiencing the North from a Feminist Perspective: Three Case Studies}

When flying from Europe to Northern America, the numerous icebergs in the North Atlantic Ocean can easily be spotted on a clear day. Are they just indicators of a hostile environment, or also of the melting ice cap? With the exception of a few Inuit settlements and the Gulf Stream-influenced regions, regular human life near the Arctic Ocean is extremely rare, yet the increasing opening of the previously impassable Northwest Passage on the North American coast is a visible marker of climatic change and the increasing accessibility of the region. Starting in the 1990s, a different alteration has occurred in the 
northern section of the North Atlantic with the collapse of the cod population, on which fisheries from Newfoundland to Iceland and Ireland have depended, which exemplifies how environmental change effects human life on numerous levels. Hall notes that not only the maritime environment, but also the land surface is highly fragile in this region, as the extremely fertile lava surface is only covered by a small layer of soil that is constantly threatened by human-induced wind erosion. ${ }^{21}$

The natural elements, such as the ocean in Björk's 'Mouth Cradle' (Ingólfsson), are a recurring theme in the subsequent articles by Arni Hemir Ingólfsson, Marie-Anne Kohl, and Denise Von Glahn, while shifting the focus of analysis from theory towards environmental perspectives through music within female artistic expression in the late twentieth/early twenty-first century, thereby pointing to the remarkable number of female performers and composers who have addressed issues of Nordic nature and climate change.

Current approaches, such as the radical perspective of ecofeminism, have raised particular awareness of a certain female sensitivity toward environmental changes, yet also of the interconnectedness between environmental developments and broader issues in society. French feminist Francoise d'Eaubonne (1920-2005) in Le Féminisme ou la Mort (1974) suggested that ecofeminism equates the exploitation of the environment with the repression—or general situation—of women. For instance, women in less developed countries_-often head of the family households—are often greatly affected by environmental problems, e.g. deforestation, water pollution, and environmental toxins, a view that has long been supported in radical feminist literature. ${ }^{22}$ While criticized for the emphasis on gendered dichotomy, d'Eaubonne's radical ecofeminism thereby established a more nuanced and socially oriented perspective that has been taken up in the environmental sciences.

This interconnectedness between environment and gender has also been taken up by the United Nations with regard to subsidence cultures. Specifically, the United Nations Inter-Agency Network on Women and Gender Equality illustrates how women in sub-Saharan regions are often affected first-andforemost by environmental problems, as their work is often tied to the presence of biodiversity. ${ }^{23}$ Along similar lines, while addressing the Arctic and North, is Rasmus Ole Rasmussen's study of Inuit cultures, which shows how environmental and related sociocultural alterations have resulted in extreme social

21 Olafur Arnalds, Elin Fjola Thorarinsdottir, Sigmar Metusalemsson, Asgeir Jonsson, Einar Gretarsson, and Arnor Arnason, Soil Erosion in Iceland (Reykjavik: The Soil Conservation Service and the Agricultural Research Institute, 2001).

22 See also Greta Gaard and Lori Gruen, "Ecofeminism: Toward Global Justice and Planetary Health," in Environmental Philosophy: From Animal Rights to Radical Ecology, eds. Michael E. Zimmerman, J. Baird Callicott, John Clark, Karen J. Warren, and Irene J. Klaver, 4th ed. (Upper Saddle River, NJ: Prentice Hall, 2005), $155-157$.

23 UN WomenWatch, "Fact Sheet. Women Gender Equality and Climate Change," United Nations 2009. http://www.un.org/womenwatch/feature/climate_change/downloads/Women_and_Climate_Change_Factshe et.pdf (accessed 1 August, 2018). 
situations, apparent, for instance, in alcohol problems, mental problems, and rape of women. ${ }^{24}$ Yet while the focus on environment and gender is of great relevance, Natalia Kukarenko argues that, ${ }^{25}$

despite the evidence provided by many researchers on differentiating effects of climate change on wellbeing and health of women and men, gender perspective remains of marginal interest in climate change, environmental and health studies. At the same time, social sciences and humanities, and gender studies in particular, show little interest towards climate change impacts on human health in the Arctic.

Thus to focus on the interconnectedness between environment and gender remains a pressing topic because, as a report by the Global Gender and Climate Alliance points out, "women are not well represented in decision-making processes, which constrains their ability to meaningfully participate in decisions on adaptation and mitigation." ${ }^{26}$ Music is one possible way to get those women's voices heard; indeed, music may be a particularly suitable means that allows women to express their specific sensitivity to their changing environment. This concern is reflected in this volume, which showcases a remarkable number of female composers and performers who have employed an impressive range of musical tools, visions, and perspectives in contemplating about and depicting the Nordic environment and its transformations.

In particular, Arni Heimir Ingólfsson, Marie-Anne Kohl, and Denise Von Glahn each illustrate how female artists hear and perceive nature sonically, and express themselves through their compositions and performances. While going well beyond gender issues, each article exemplifies how-through specific musical examples — one can learn about nuanced changes in the environment and the fragile relationship between humanity and nature. For instance, Árni Heimir Ingólfsson's analysis of 'Mouth Cradle' by Icelandic artist Björk from her album Medulla shows how she links her articulation of female identity and nature in the North. Marie-Anne Kohl similarly focuses on female vocal styles, while exploring how

\footnotetext{
${ }^{24}$ Rasmus Ole Rasmussen, "Gender and Generation: Perspectives on Ongoing Social and Environmental Changes in the Arctic," Signs: Journal of Women in Culture and Society 34, no. 3 (2009): 524-532.

Georg Witschel, Ingo Winkelmann, Katrin Tiroch, Rüdiger Wolfrum, eds.: New Chances and New Responsibilities in the Arctic Region (Berlin: Berliner Wissenschaftsverlag, 2010).

${ }^{25}$ Natalia Kukarenko, "Climate change effects on human health in a gender perspective: some trends in Arctic research," Global Health Action 4 (2011):

http://www.globalhealthaction.net/index.php/gha/article/view/7913 (accessed 1 August, 2018).

${ }^{26}$ United Nations, Global Gender and Climate Alliance, "Asia and the Pacific: Overview of linkages between gender and climate change,"

http://www.undp.org/content/dam/undp/library/gender/Gender\%20and\%20Environment/PB1-AP-

Overview-Gender-and-climate-change.pdf (accessed 1 August, 2018).
} 
American vocalist Meredith Monk (Facing North) and Björk tap into the art vs. nature ideal through their shared notion of the "natural voice" as a primal force, which serves both artists as a tool for creating their art. While both Kohl and Ingólfsson render the voice as central here, the "loudest" voice is probably that of Björk, whose work, while often rooted in Icelandic politics (evident in her artistic activism against the export of Icelandic Aluminium in 2008), has particularly addressed environmental issues, including the transformation of the fishing industry that resulted from Iceland's 2008/9 financial crisis. Thus through artistic means available to her, Björk has played a critical role in raising public awareness of environmental issues, including global warming.

Gendered perspectives are also the focus of Denise Von Glahn's analysis of Libby Larsen's musical composition $U_{p}$ Where the Air Gets Thin, which was inspired by the fundamental force of air and the glacial world of the Himalayas' Mount Everest. In doing so, Von Glahn illustrates different forms of interaction with nature and the wider world, in particular the global debate on climate change as also reflected in Switzerland's Grindelwald's glacial melting. All of the articles presented in this EJM volume thus enhance an understanding into the deepest levels of how humans experience nature, and how they see themselves in relation to nature within the context of current climate change.

\section{From Romanticism to Sustainability: Thee Examples of Human Interaction with Nature in Extreme Environments}

[G]laciers work apart from men, exerting their tremendous energies in silence and darkness, outspread, spirit-like, brooding above predestined rocks unknown to light, unborn, working on unwearied through unmeasured times, unhalting as the stars, until at length, their creations complete, their mountains brought forth, homes made for the meadows and the lakes, and fields for waiting forests, earnest, calm as when they came as crystals from the sky, they depart.

In his New York Tribute article on "Yosemite Glaciers" (December 5, 1871), ${ }^{27}$ the Scottish-American naturalist John Muir (1838-1914) points out some key features of the northern landscape-glaciers, mountains, forests, yet also silence, which are the focus of the final three articles. More specifically, while glaciers still cover $11.1 \%$ of Iceland, which is also home to Europe's largest glacier Vatnajökull, John Muir pointed out that the glacial sound world is in reality loud, yet people often associate such nature with silence. Moreover, while human technology seems to have no place in such a rough natural environment, Icelandic culture has combined modern technology and nature in striking ways. Early settlers arriving from richly forested regions of Scandinavia also noticed the lack of woods on the island,

${ }^{27}$ John Muir, "Yosemite Glaciers," New York Tribune (December 5, 1871). Reprinted on the website of the Sierra Club: http://vault.sierraclub.org/john_muir_exhibit/writings/yosemite_glaciers.aspx. (accessed 1 August, 2018). 
thus early heating was dependent on turf, sheep dung and, later, imported fossil resources. In current times, a road trip from Keflavik Airport to the Reykjavik area instantly shows the striking energy transition in modern Iceland, which is today covering 99\% of its needs with geothermal energy and hydropower.

The final last three articles illustrate that the sonic context and sound imageries can help to gain a deep insight into the variety_ and possibilities_ of human relations to specific environments of the North: the woods in Northern Scandinavia (Tina K. Ramnarine), the Icelandic environment (Matthias Tischer), and the glacial mountain world of the Swiss Alps, all of which share many features of the Arctic (Britta Sweers).

Tina K. Ramnarine's study of "Music and the Northern Forests" focuses on cultural and ecological sustainability as linked through music, language, and identity politics. Discussing the work of Finnish artists like composer Jean Sibelius, Forest Folk musicians, new folk groups like Värttinä, and Russian-Karelian folk rock, Ramnarine also adds minority perspectives in global thinking about cultural survival and the environment. Matthias Tischer's subsequent reflection on "Recreating the Creation" once again turns to the representation of Icelandic nature in music by analyzing the alteration of Sigur Rós's album Von in the process of a re-recording. Tischer expands the idea of sustainability towards the concept of the re-mix, also analyzing the role of technology and silence in this process. The final article on "Alpine Song and Sound Impressions" by Britta Sweers returns to the Swiss Alps (as in a previous article by Von Glahn). The environmental changes in the Alps, which share climate conditions similar to the Arctic, have become particularly visible as the region was shaped by tourism and urbanization. Thus, musical articulations ranging from yodeling to rap and hip hop bands reflect these altered human relationship with nature.

In each of these cases, musical encounters with extreme environments reflect the versatile interrelationship of human culture and nature, which ranges from musical perception of nature as a spiritual site, to nature as a threatening space, and to nature's impact on the emergence of (musical) sustainable action. Each article thereby also reflects the human position toward nature through the analysis of musical concepts in performances and compositions. Resonating with Muir's ideas, this can range from nature without humans toward the co-existence or integration of the human into nature, perspectives that are reflected in perceptions of musical performance as "nature-bound," or in the integration of technological devices to express natural concepts. In these extreme contexts, the relationship between nature and technology, tradition and mediatized or popular music forms can be problematic, which is evident in the use of hydropower and also highlighted in Sigur Rós's Heima. Yet 
both nature and technology are not necessarily always oppositional aspects, which is clearly evident in the aforementioned geothermal energy and the music making by sound artists, in particular Björk, who often expresses her environmental concerns via electronic and digital technology. This equally applies to perceptions of silence (often a marker of the absence of civilization) and loudness (as an indicator of urbanization), since in reality nature is never silent (in the sense of sonic quietness). What kind of silence do listeners thus experience? And how is it constructed in musical performance and listeners' imagination? Indeed, all three articles point to the constantly changing relations between humans and nature, while focusing on a particular contemporary situation and its mutable nature, and integrating a historical perspective to depict this highly versatile relationship. The authors thereby reflect on long-term local strategies for addressing the uncertainties of global threats, such as climate change in northern environments.

It seems that while environmental change calls for a reconsideration of the changing boundaries between humans and environment, this is likewise true for academic boundaries, not only with regards to the objects studied, but also concerning the theoretical perspectives and methodologies. The final two articles by Ramnarine and Sweers have been written from an ethnomusicological perspective, yet a fuller understanding of the complexity of the changing boundaries between humans and environment is only possible via a broader interdisciplinary approach that combines, for instance, ethnomusicology and historical musicology. Tischer's article is thus interdisciplinary, combining insights from aesthetics and historical musicology with popular music analysis. Each of the authors clearly hint at the necessity of interdisciplinary dialogue, and while this would enable the musicological disciplines to speak out more loudly in the global climate debate, it would also allow developing new long-term theoretical perspectives within the increasingly economically-driven discourses in academia.

John Muir's quotation seemed an apt introduction to the last three articles. Dedicated to establishing the United States' nature reserves and wilderness protection, Muir was deeply concerned with environmental issues and sustainability for more than a century. The articles here further highlight the complexity of sustainability. Rooted in the Latin word "sustinere" ("maintain," "endure"), "sustainability" points to long-term strategies and methods that seek to stop the complete use or destruction of natural resources. Yet the articles also remind us that the origin of sustainability is not culturally or globally homogenous, even within the European-American context. For instance, the German mountain administrator Hans Carl von Carlowitz (1645-1714), one of the earliest authors who used sustainability as a term in his book on Silvicultura oeconomica (1713), initially developed this concept within the economic context of forestry while describing sustainability as a "forestry princely, according to 
which no more wood can be chopped than what can respectively re-grown again." 28 Subsequently, the concept of sustainability became associated with more ecological-biological perceptions of systems that manage to endure and remain diverse and productive. Only fairly recently is sustainability understood as a cultural concept, as was apparent in the UN Resolutions of the World Commission on Environment and Development (Brundtlandt Commission) in 1987 where "sustainable development" was defined as "development that meets the needs of the present without compromising the ability of future generations to meet their own needs." ${ }^{29}$ More recently, sustainability was the keyword of the 2002 UNESCO World Summit on Sustainable Development in Johannesburg.

Given these varied conceptual perceptions and contexts, it is clear that in the case of music the transformation of such concepts as sustainability from nature to culture might not always be as clear-cut. As Tischer outlines, sustainability goes far beyond fixed ideas of culture, as it can also be musically expressed in remixes and recycling, which similarly involves transformation, and this in turn raises questions of authenticity. Both Ramnarine and Sweers thus illustrate the way that authenticity is expressed in the continuing search for old and new, which is also at the core of an environmentally-conscious life, not only in the North, but indeed also anywhere around the globe.

\section{Outlook}

The North as a place is often conceptualized via a combination of philosophical, cultural-sociological, imaginative, and political readings. Within this context, the articles presented in this EJM volume provide insights into the versatile and multi-faceted, yet likewise fragile relationship between humans and nature in this region. It is the aim of this collection to enhance discourses on global warming and climate change in Europe, especially its Nordic countries, and the United States; to open up musicology to studies of global climate through music; and to contribute to this newly emerging field of study within cultural theory, musicology, ethnomusicology, and sustainability studies. As the German philosopher Ludwig Wittgenstein remarked, "the facts all belong only to the task/and not to its performance." 30 There are indeed larger spaces to move within, wider horizons to think about, and deeper dimension to observe than one might think.

\footnotetext{
28 "forstwirtschaftliches Prinzip, nach dem nicht mehr Holz gefällt werden darf, als jeweils nachwachsen kann." Hans Carl von Carlowitz, Sylvicultura oeconomica. Anweisung zur wilden Baum-Zucht (Leipzig: Braun, 1713), 105. Cf. entry "Nachhaltigkeit." Duden, Deutsches Universalwörterbuch, 4th ed. (Mannheim: Duden, 2001).

${ }^{29}$ United Nations Documents, From A/42/427. Our Common Future: Report of the World Commission on Environment and Development: "Our Common Future, Chapter 2: Towards Sustainable Development." IV: Conclusion. http://www.un-documents.net/ocf-02.htm. (accessed 1 August, 2018).

30 "Die Tatsachen gehören alle nur zur Aufgabe, nicht zur Lösung” (6, 4321). Ludwig Wittgenstein, Tractatus logicophilosophicus [Logisch-philosophische Abhandlung], transl. Frank Ramsey and Cecil K. Ogden (London: Routledge \& Kegan Paul, 1922).
} 


\section{Acknowledgements}

I am very grateful to Simone Krüger Bridge, Katrin Losleben, Annette Kreutziger-Herr, as well as to Julia Jordi, Josh Kenworth, and Addrich Mauch.

Britta Sweers, November 2019

This publication was generously supported by the Mariann Steegmann Foundation.

\section{Mariann Steegmann Foundation}

